\title{
Evacuation egress in high rise building: Review of the current design evacuation solution
}

\author{
Hazrina Mansor ${ }^{1,}$, Yazmin Sahol Hamid ${ }^{1}$, Nurul Huda Suliman ${ }^{1}$, Nursafarina Ahmad ${ }^{1}$ and Noorfaizah Hamzah ${ }^{1}$ \\ ${ }^{1}$ Senior Lecturer, Faculty of Civil Engineering, Universiti Teknologi Mara (UiTM) Shah Alam, Selangor.
}

\begin{abstract}
In the aftermath of the September $11^{\text {th }}$ attack, design of tall buildings particularly in the aspect of safety systems and structural robustness, arguably the most crucial issues that is deliberated till to date. Concerning the safety systems specifically on evacuation egress, many novels and innovative evacuation solutions for high rise buildings that have been researched and put forward, for instances Platform Rescue Systems (PRS), Controlled Descent Devices (CDD) and Escape Chutes. Still, the practicability of the existing proposed egress systems to be implemented in the real-life situation and its compliance with the tall building design legislation remain unknown. For developing countries such as Malaysia and United Arab Emirates, tall buildings play a role as an iconic landmark. While countries like China and Hong Kong, tall building is needed due to the scarcity of land and high populations. As more than one hundred tall structure exists in the world, and will be increasing by 2020; therefore, it is urgently needed that existing engineering practices in designing tall building to be reviewed with respect to evacuation egress. The main objective of this paper is to create awareness among developers, consultants and contractors that proper evacuation egress in tall building design and development is a must. This paper provides a comprehensive review of the existing engineering practices on tall building evacuation planning systems and design. Furthermore, the effectiveness of the currently proposed systems and its consideration amongst structural and safety engineers are also reported.
\end{abstract}

\section{Introduction}

There are more than one hundred tall building structures exist in the world and will keep increasing by 2020 . The increase in the number of developed tall buildings across the globe started in the year of 2015. The total number of the tall building completed in the year alone was founded to be 106 tall buildings which surpassing the 2014 record that was 99 buildings completed [1]. The statistics show in Figure 1 highlighted that majority of the country within the Asian nation has dominated the statistic of the growth of tall building particularly in China [1].

The increase in the number of the tall building is believed directly associated with the rapid growth of population and urbanization. A study conducted by Markus Schläpfer and Luís M. A. Bettencourt of the Santa Fe Institute and Joey Lee of the University of British Columbia in 2015, concluded that "larger cities have on average taller and bigger buildings as an adaptation to higher population and employment densities and levels of income" [2]. However, the risk that allied with this type of property is significantly high when it comes to fire incidents.

In most cases, the fire accidents happened in high-rise building result in catastrophic loss of human life and property, occupant's injury and damage to some part of the property. While fighting a fire to safe property and life is a standard method to defeat the burning fire, however in certain circumstances, the approach seems ineffective as part of the property have already burnt and event worst it imposes a significantly high risk to a firefighter. Thus, the most appropriate solution to the risk of fire in high-rise building should be considered as early as on its critical conceptual design stage. On the conceptual design stage, Architects and Engineers are suggested to emerge with the idea considering a design that comes with the appropriate level of safety measure per engineering and legislative requirement, including the installation of systems to mitigate against all potential causes of fire and after that be continuously maintained [3]. Still, the major concern is; does Architectural design is keeping up with the needs of fire safety design revolution in tall building? [4]

\footnotetext{
* Corresponding author: $\underline{\text { hazrina.uitm } @ \text { gmail.com }}$
} 
It is undesirable to see the future advanced tall building, is still relies on ordinary staircases for emergency evacuation route [5],[6]. Therefore, in this paper, comprehensive review of the existing engineering practices on tall building evacuation planning systems and design are discussed. In addition, it also aims to create awareness among Architects, consultant's engineers and contractors that proper evacuation egress in tall building design and development must be incorporated at the fundamental design stage.

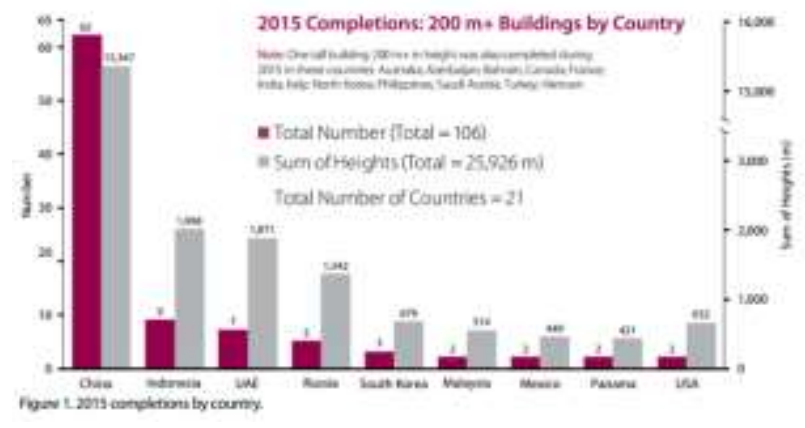

Fig. 1. 2015 tall building completion by country [1]

\subsection{Notable Fire Incidents}

Safety awareness of the emergency evacuation planning system in a tall building is often being neglected. Without a proper evacuation planning system, occupants would not be able to evacuate themselves in all the possible emergency cases occur for instances of earthquakes, sabotage and terrorist attacks. For such emergency situations, emergency preparedness is vital as the circumstances involved a vast number of people evacuating. Moreover, the emotional panic attack among the occupants will also contribute to a crisis and long evacuation time taken during evacuation process [6], [7]. The importance of incorporating fire safety design in the building and the needs to inseminate fire safety culture among the high-rise building's residential are herein discussed based on the selected notable fire incident tragedies in the past.

Among the earliest notable fire incident that worth to be highlighted here is the fire disaster at Daeyeonggak Hotel. The incident was claimed due to careless fire management of the buildings and the building materials [8]-[10]. The building flaws including poor emergency escape route, whereby the designed of the two internal staircases were not meant for emergency fire exit, nevertheless were designed as an alternative of lift failures [8]-[10]. In addition, the dysfunctional of intelligent safety features such as exit lights was also blamed for the cause of many occupants trapped and were unable to escape during the event.

Another notable tragedy was the 2010 Shanghai fire which had destroyed a 28-story high-rise apartment building, killing at least 58 people [11] and injuring more than 70 [10]. The fire triggered from the welding sparks operated by unlicensed welders on the building [11]. During the event, the firefighters faced a significant challenge to stop the fire as the water hose was not long enough to channel. the water up to above the 85 meters height tall from the ground [11]. This issue has put forward the importance of considering a route for firefighters to internally or externally access the highrise building in the event of a fire.

Later in 2017 , the world was rocked by a massive fire engulfed at a west London residential tower block, Grenfell Tower (refer Figure 2). The notable incident has caused high numbers of fatalities with unofficially being reported in [12]-[14] was at least 12 people dead and 75 injuries [12]-[14]. The fridge-freezer and outside cladding are claimed to be the spark of the blaze. It was reported that the cladding was a recent innovation design which failed under the fire-safety test [12]-[14]. The failure to evacuate the occupants are due to the poor evacuation planning system of the building. The Grenfell Tower, residential block encompassed a 24 stories apartment with four levels were designed for mixed community areas and the remainders 20 floors were designed for the residential apartment. Figure 2a, Figure $2 \mathrm{~b}$ and Figure $2 \mathrm{c}$ show the plan view of each of the mixed community and the residential levels respectively. From the figures, it is shown that the emergency escape route designed for the building was limited to a single staircase. Such limited escape route triggered a chaos scenario, as the occupants and firefighters are both using the same staircase with the occupants were rushing to the ground while fireman was climbing upward to save the life of peoples inside the building. Also, the confined spaces located at the core of the building was also believed as a poor designed for emergency evacuation planning. Apart from the poor design of the building, the fast spreading of the fire was also blamed for the combustible material type of cladding used for the building [12-14]. The tragedy happened on the Grenfell tower highlighted that, it is vital for all buildings to undergo a high level of scrutiny at the time of design, construction, and operation. A thorough investigation on the Grenfell apartment is undoubtedly needed in helping to shape the future of high-rise design in global.

About two months after the Grenfell Tower's incident, on August 4, 2017, a new fire episode was reported occurred at Torch Tower, Marina, Dubai. The incident has been due to cigarette butts being thrown into a potted plant which began to smolder until it caught fire and electrical fault [17]. The tower has experienced two series of severe fires incidents since it started to open for public in 2011[18]-[19]. The first was in February 2015 and the second was in August 2017. In contrast to the chaos fire incident happened on the Grenfell Tower, the Torch Tower fire incident was somewhat under control, without any injuries or casualties. The key factors that lead to the successful fire evacuations at the Torch Tower, Dubai are due to the excellence evacuation planning strategy and the structural safety design considered in designing the Torch Tower building. Lesson learnt from the Torch Tower tragedy highlighted 
that illegal practices, lack of knowledge, and certain habits within the community are the cause of fires. Besides, it has proven that with frequent awareness campaign and practices on fire evacuation drill will help residents to understand better the importance of evacuating buildings quickly and safely [19]. Also, 'fire compartment strategy' which is constructed with fireresistant features, such as automatic doors or barriers throughout floors that are designed to slow fires has set a new design evolution on high-rise building safety design.

The incident happened at Pusat Tahfiz Darul Quran Ittifaqiyah (refer to Figure 4) on 14 September 2017 has gained considerable attention among the researchers for the need of safety evacuation egress not only for high rise building but also for low rise building like double story houses and bungalow. The Pusat Tahfiz was a three storey building and had blown on fire by a group of local's teenagers. The reason of the sabotage was due to the revenge following the incidents of taunts between the group of locals' and the Pusat Tahfiz Darul Quran Ittifaqiyah's students [20]. During the fire event, the students had trapped inside the building as the fire had blocked the entrance and the windows were fitted with bolted grills (refer Figure 5). The metal grill which is fixed into the wall is commonly use in most of the houses in Malaysia for many security reason purposes. Here the practicality of the metal grill windows is questioning. Shall the use of the metal grill windows be omitted in the future? As the existence of the metal grill window will prevent the occupants to escape themselves in the emergency event or incase of the occupants being trapped. Besides, what would be the alternative egress for such building, if such tragedy is happening again?

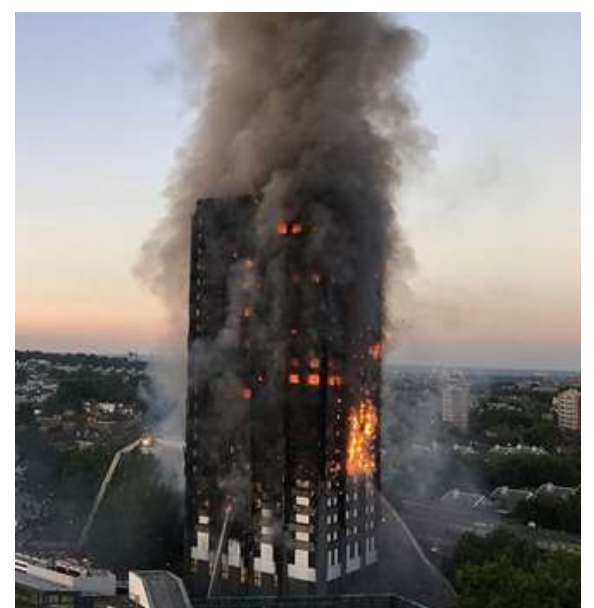

Fig. 2. Grenfell Tower on fire [15]

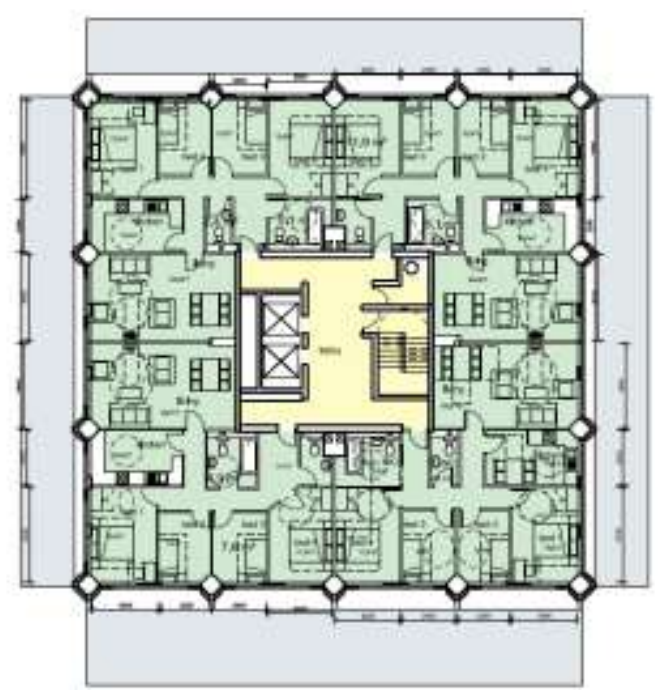

Fig. 3a. Office floor level [16]

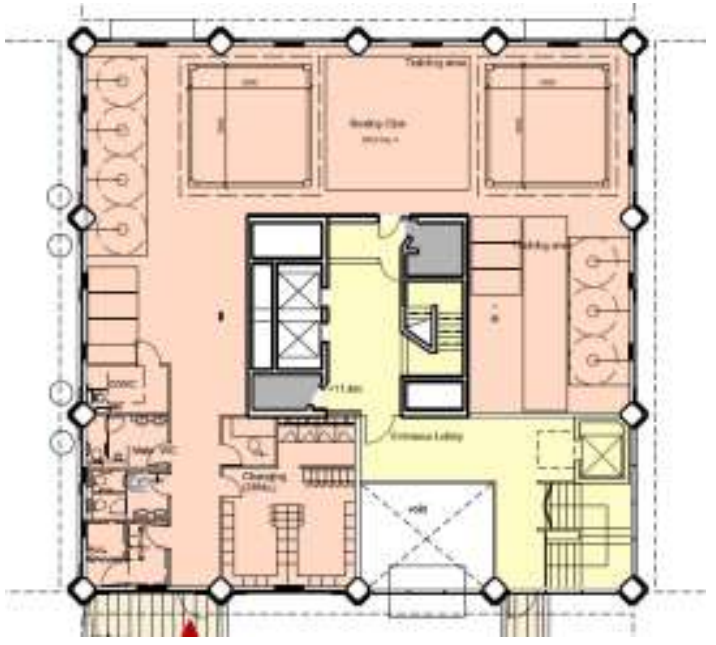

Fig. 3b. Walkway floor level [16]

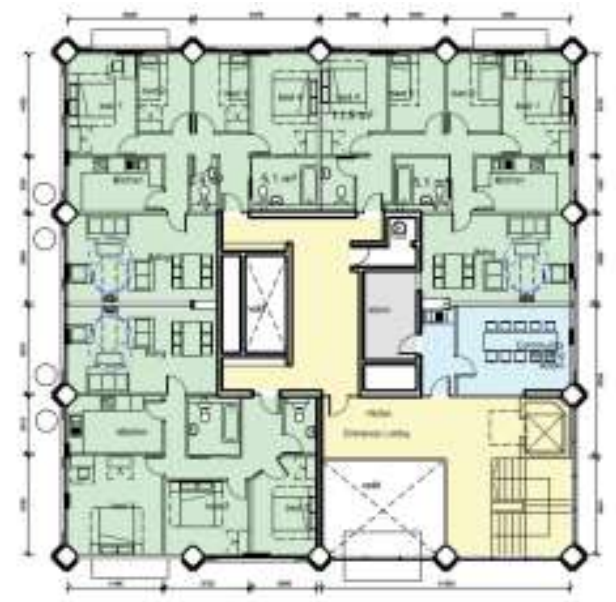

Fig. 3c. Mezzanine floor level [16] 


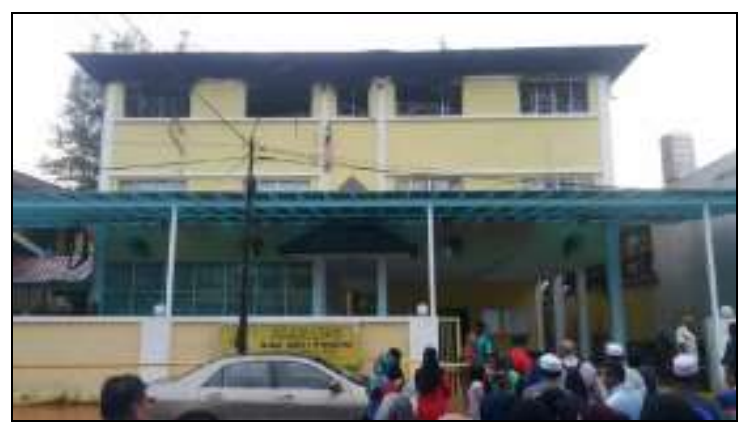

Fig. 4. Pusat Tahfiz Darul Quran Ittifaqiyah [21].

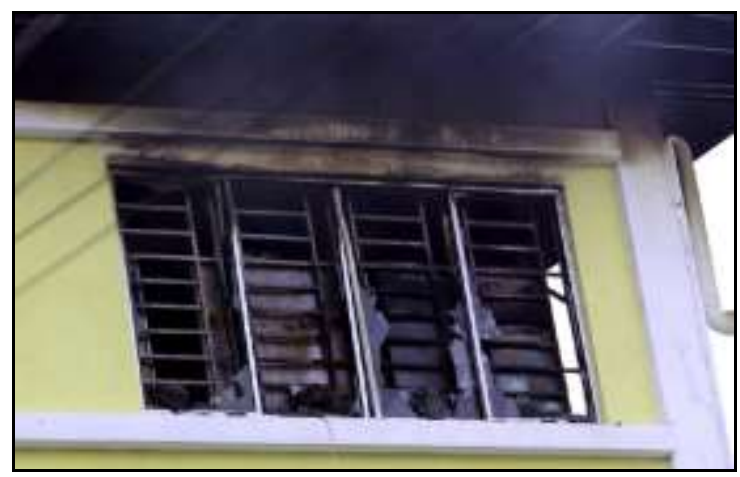

Fig. 5. Bolted metal grill window [22].

\section{Fire safety design and evacuation guideline for high-rise buildings}

\subsection{Fire safety design}

History shows that the selected tragedies happened in the past have raised a greater sense of awareness on the fire safety evacuation topic. Ever since the collapse of the World Trade Center Tragedy on September 2001, research related in developing ways to establish the international fire safety design codes on tall building is actively participated by many researchers and professionals all over the world. Afterwards, the engulfed fire on the Grenfell Tower tragedy has caused even more significant interest in the challenges of tall buildings. Researchers have put forth many dialogue questioning on egress and evacuation system, emergency access, communications and situation awareness, fire resistance design, resiliency and reliability of water supply and active fire protection systems of the tall building[23].

In general, there were no guidelines on the fire safety designs that formed explicitly for high-rise building before the most infamous tragedies happened in 2001. Practically, most of the countries have their own local or national codes and standards. Typically, the national fire safety design codes are developed based on the previous local experience of fire incidents happened in the particular country. For instances, in Malaysia, the evacuation plan and fire safety design consideration for a building has been clearly stated in the Uniform Building by Laws 1984 (UBBL 1984)[24]. In the UBBL 1984, the document has set requirements/rules that are mandatory for architect, engineer and developer to comply to receive approval from the local authority. The UBBL 1984 is similar to all others international buildings codes, which cover a broad range of buildings conditions, yet it is anticipated not to reflect innovation in design as the guideline provide only minimum requirements for fire safety design for the high-rise building. In fact, the international fire safety guides and practices such as 'Fire Safety Engineering Approach' and 'Performance Based Criteria' were adopted in conjunction with the UBBL 1984 during the development of the most worlds' tallest twin tower building, Kuala Lumpur City Centre (KLCC) in Malaysia. Since then, in 1999 fire safety building guideline in Malaysia was developed, which specifically mentioned in clause 3.8, that "the UBBL 1984 and the Fire service Act 1988 should not be read in isolation, but should be read in conjunction with all relevant Malaysian and International legislation and standards".[24]

Meanwhile, the provision on the fire safety design outline in the Approved Document B (2006) to the Building Regulations appears to be almost similar with the UBBL 1984 and the International Building Code (IBC) USA respectively [25],[26]. All of which provide prescriptive design rules and guidelines on physical geometry of the escape route for the designed building such as staircase riser, step dimensions, travel distance, fire-resistive construction, active suppression and alarm systems, egress, and smoke management. The prescriptive design approach was crafted to mainly focus on life safety, in which ignore the risk consequences upcome during and after the fire incident; for instances the cost of disruption to an operational process arising from fire and the performance of the building and its occupants under fire. It is worth to highlight that if the tall building is designed only based on the prescriptive design rules, thus the real performance of the structural resistance, smoke distributions and total evacuation structure under fire would not possibly be known until the real fire incidents occur on the designed tall building. For examples; fire incidents in the One New York Plaza on August 15, 1970, has led to the improvements in the elevator code, specifically on the automatic elevator recall [25]. Aftermath the tragedy, it is emphasised that fire or smoke should not activate elevator call buttons. Since the event, it is required that a durable material should protect steel members. The issues on the automatic elevator recall and the needs of steel members to be covered by durable would not be raised up in fire safety design codes if the fire incidents on the One New York Plaza did not occur. Similarly, the lesson learnt on the need of sprinkler protection to have redundant water supply for high rise building only be realised repercussion of the One Meridien Plaza fire incident in 1991 [25]. Another fire incidents that significantly contributed to the improvement of the prescriptive design guidelines of high rise building are the terror attack on the World Trade Center building 1 and 2. The incident highlighted that in ensuring safety design 
practices for high-rise building, consideration is not limited only by the threat from fire, a broad range of coverage also should include various emergency scenarios. The outcome from the tragedy has proposed the requirement of structural redundancy design for structural framing system and evaluation on the fire safety system that can adhere to fire and impact. Also, due to high fatalities involved, it is accentuated that egress system should be evaluated for redundancy and robustness to ensure total evacuation. Fire protection ratings and safety factors for structural transfer should also be evaluated for adequacy.The issues on the redundancy required for frame structure design have been well documented in the General Service Administration (GSA) [27], Department of Defence (DOD)[28] and Approved building document A[29], United Kingdom. The documents all of which address means of designing and analysing the structure using both the prescriptive design rule and the performancebased method. It is also an urge to establish the unified references for fire simulation design and guideline of the tall building, in which; the document is expected to provide the 'prescriptive design rules comprehensively', Fire Safety Engineering Approach' and 'Performance Based Criteria' guideline for being used in global.

\section{Review of the current existing alternative evacuation egress for high rise building}

For a tall building, total evacuation time taken for occupants to come out from the building safely is vital. It is well understood that the risk of occupants to evacuate themselves during the emergency evacuation circumstances, are limited due to the height of the building and the availability of the egress evacuation. Above specific heights, the vertical distance to be travelled by an occupant including those who are disable and older people are not possible when adopting the traditional method of evacuation using only stairways. In such instances, the proposed egress system may require re-evaluation to consider alternative strategies [5].

Apart from the improvement of existing systems such as fire stairs and elevators for the fire escape, there are many novels and innovative evacuation solutions for high rise buildings that have been researched and put forward by some individuals and some organisations. For instances [30], Platform Rescue Systems (PRS), Controlled Descent Devices (CDD) and Escape Chutes (Refer to Figure 6, Figure 7a, Figure 7b, Figure 8a and Figure $8 \mathrm{~b}$ ). The ideology of the alternative evacuation egress mentioned herein, seemingly come from the concept of the existing emergency system such as those applies for the ship, aeroplane and oil and gas industries. The design ideology used for the PRS can be said almost like the 'safety lifeboat' use for the ship during the emergency evacuation. For the ship, the safety boat is hanging on the side of the boat and use only during the emergency evacuation (Refer Figure 6b).

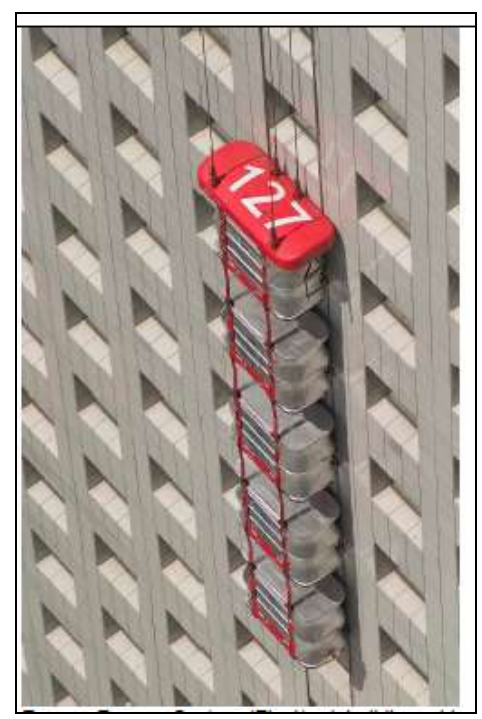

Fig. 6. Platform Rescue System [10].

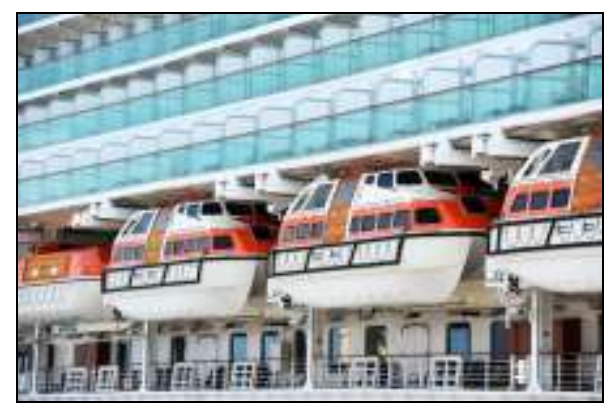

Fig. 6b. Hanging safety life boat [33].

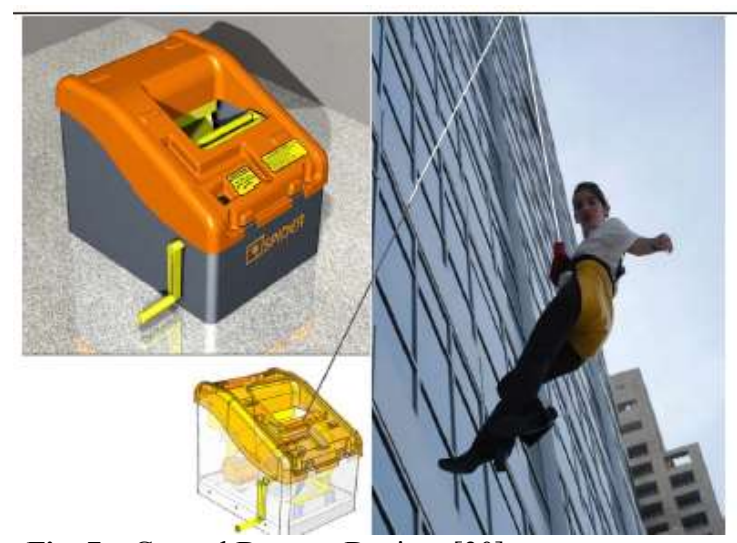

Fig. 7a. Control Descent Devices [30].

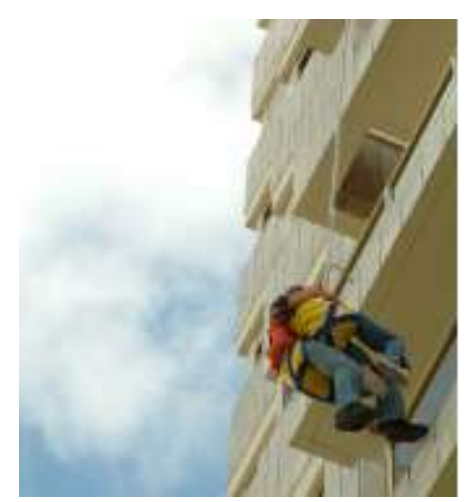

Fig. 7b. Control Descent Devices [30]. 


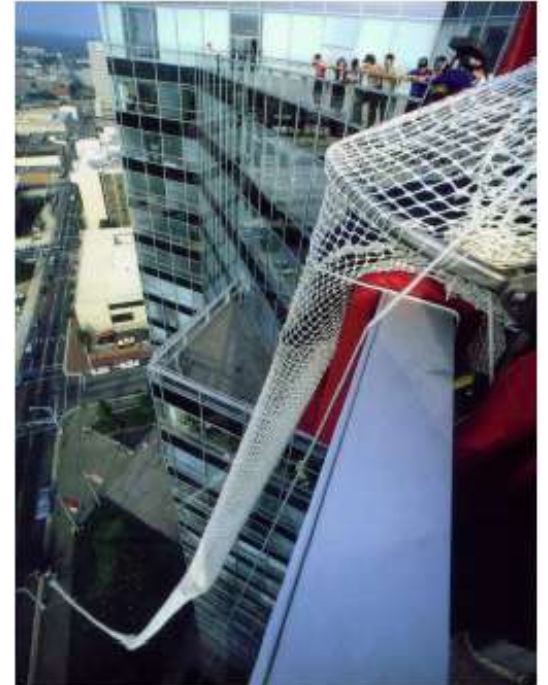

Fig. 8a. Escape Chute Devices [30].

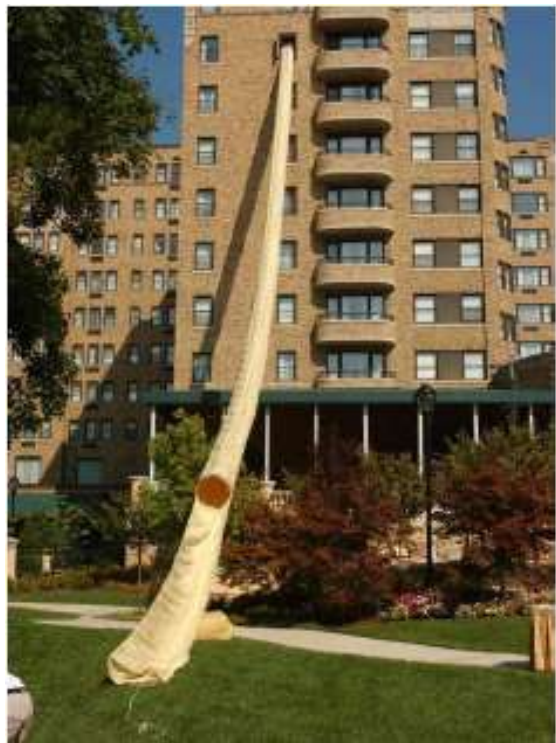

Fig. 8b. Escape Chute Devices [34].

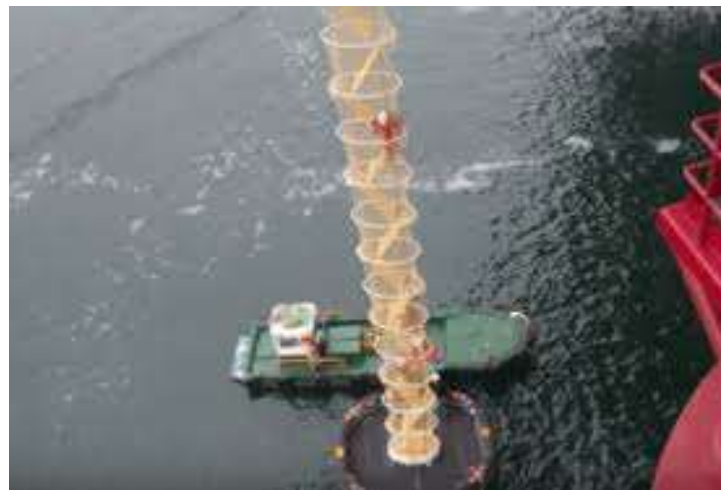

Fig. 9. Escape Chute used in offshore [35].

Similarly, the PRS system is installed at the rooftop of the building whereby the system is unfolded down through cable during emergency evacuation (see Figure 6a). Detail of the PRS can be found in [6]. The first PRS prototype was installed on the 21-story building in Ramat Gan (Israel) in July 2004 [30]. Meanwhile, the conceptual design of the escape chute evacuation egress for the building is almost equivalent with the escape chute use for the oil and gas industry (Figure 9). The escape chute is a cylindrical or trough-shaped device typically made of fire resistant fabric or netting [6] [30]. Each chute solution has its design to control the descent speed of the evacuee. Further information on the escape chute can be found in [6]. Figure $8 \mathrm{a}$ and Figure $8 \mathrm{~b}$ shows the example of the escape chute device. In South Korea, the Controlled Descent Devices (CDD) has been seen in a hotel room. The hotel room has been equipped with a box containing an abseil belt and descent line connected to the window wall, and a hammer to break glass in the event of an emergency (refer figure 10) [30].

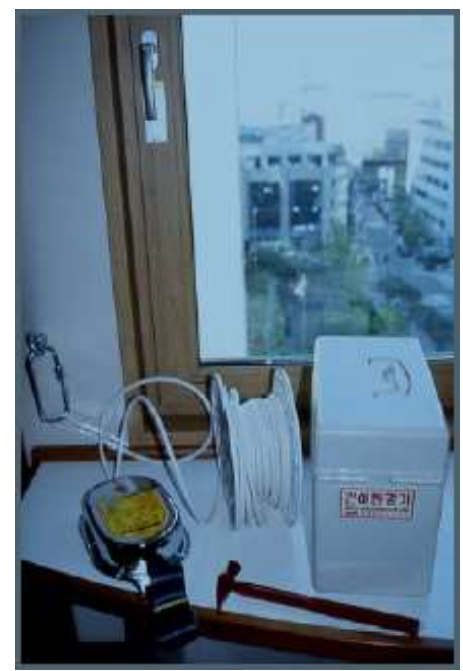

Fig. 10. Control descent device use in Korea [30].

It has been reported in [30] that there are more than twenty different brand names and companies claiming sales and/or installed of about 400,000 units around the world, mostly in Japan, Korea, Taiwan, Thailand, China, France, Spain, Germany, Italy, Sweden, Finland, Mexico, Australia and Canada [30]. Besides, it was also reported that such escape chute and CDD are mandated to be installed in buildings such as hotels, control towers and others in Japan and France [30]. Although the idea of the alternative evacuation egress has been available more than ten years ago, still the implementation and the requirement of the system are not being made mandatory for all the tall buildings. As has been addressed in [30], the alternative evacuation solution that is currently available is far from being acceptance other than to be used for a small-scale building. Further research may need to focus on the suitability of the current alternative evacuation egress and its limitation to be applied to a tall building. This includes; what is the height limit of the building that suitable to install and use the devices? Does the escape chute work during the real emergency situations? All these questions are still pending with an answer. Architect and fire safety engineer may need to integrate as early as at the conceptual design stage and come out with a tall building that can fit well with the devices.

Also, the sky bridge is another means of evacuation egress that introduce at a height to allow for horizontal escape for evacuee. The idea was to avoid the occupants 
being trapped at a certain level if a tall building effectively cuts off the connection to the ground [30].

Apart from industrial contribution, researchers also actively participated in innovatively finding the solution design for the alternative evacuation egress system. Research carried out by Prof. Myung Silk Lee from Dongguk University is among of the latest invention for evacuation egress solution (See Figure 11a and Figure 11b). The benefit highlighted of the product is; it can be used as a safety rail during the typical situation, claimed to be excellent evacuation capability, almost zero damage to building scenery, easy installation and good evacuation space [31].

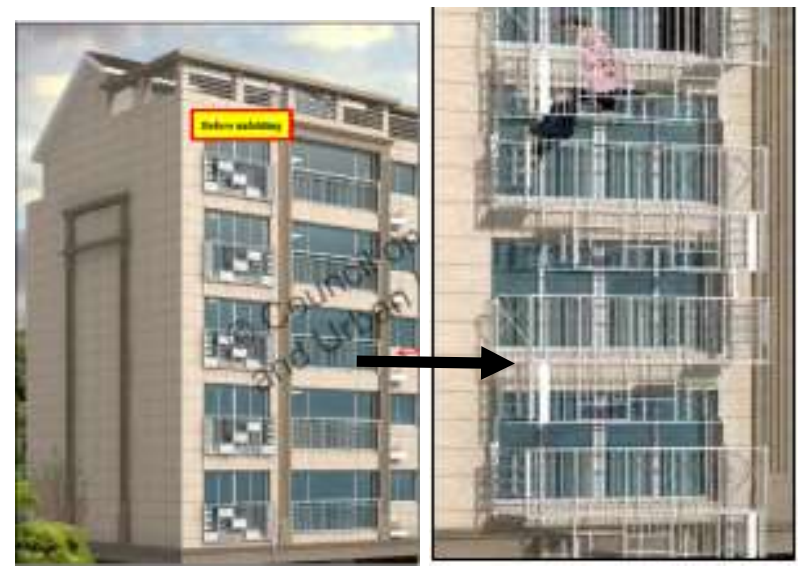

Fig. 11(a). Foldable fire evacuation staircase [31].

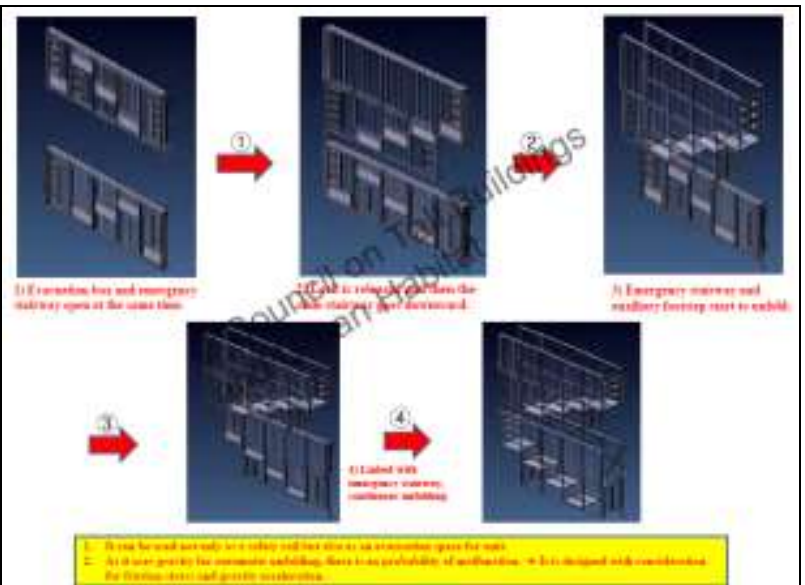

Fig. 11(b). Procedure of foldable fire evacuation staircase [31].

Another excellent on-going research study was conducted by Xin Zhang [32]. Xin Zhang study and proposed a new evacuation device for high rise buildings in a fire accident. The device is designed to have a unique spiral slideway and shunt valve. The advantage of the innovative device is that it helps in shortening the evacuation time as people could fast slide down to the first floor under gravity without any electrical power and physical strength, including mobility impaired persons. Safety protection such as protection pad needs to be used to avoid injuries caused by surface friction with the slide. The proposal of the first spiral slideway and shunt valve was terrific; however, other aspects must be taking into consideration such as where do the slide need to be installed in reality? If it is installed inside the building, the smoke-fire analysis must be conducted to ensure that the smoke does not suffocate the evacuee, and further study can be done on the friction between the slide and cloth material wear by evacuee. Also, the practicality of the unique spherical device needs to consult with the professionals to bring the novelty design from research to high-rise building practice.

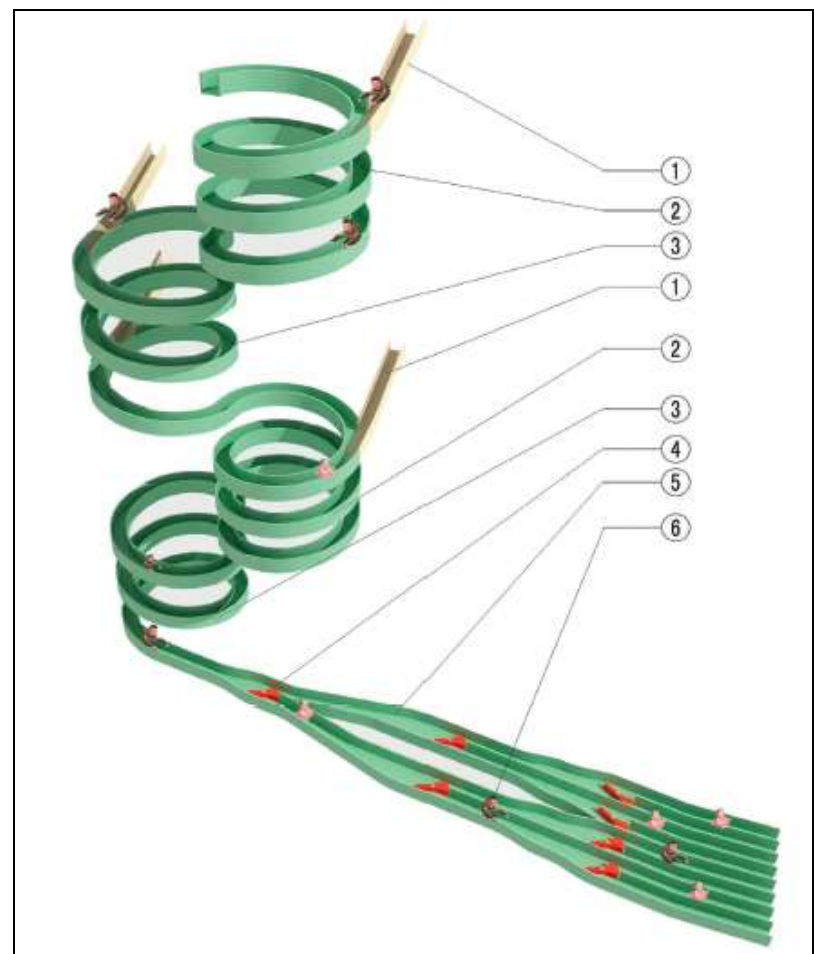

Fig. 12. Special spiral slideway device [32].

\section{Conclusion and recommendation of the potential research area}

A unified criteria system for fire safety in tall building is necessary for current and new buildings to allow for fast and easy escape. As mentioned in the article there are many existing fire escape chutes that have been developed, however all these innovative innovations have not been implement in the codes of practice of building regulations yet. Therefore, during conceptual design stage engineers and architect should work together with the building legislation to achieve a comprehensive solution for tall building with regards to evacuation strategy. Followings are the future research recommendations;

1. Investigation on the performance-based approach of the current alternative evacuations systems (CDC, PRS and escape chute) using fire and escape simulation analysis software. 
2. A survey analysis is suggested to be performed comparing all the alternative evacuation systems.

3. Further research may need to focus on the suitability of the current alternative evacuation egress and its limitation to be applied to a tall building. This includes; what is the height limit of the building that suitable to install and use the devices? Does the escape chute work during the real emergency situations?

4. A proposal on structural design of implementing fire evacuation aspects that innovatively suit for an easy fast and smooth evacuation chute for tall building is recommended.

5. Establish the unified references for fire simulation design and guideline of the tall building, in which; the document is expected to provide the 'prescriptive design rules comprehensively', Fire Safety Engineering Approach' and 'Performance Based Criteria' guideline for being used in global.

The Author would like to thank to the Universiti Teknologi Mara, the Ministry of Higher Education, Malaysia (MOHE) for the funding of the Lestari grant No 600IRMI/MyRA 5/3/LESTARI (0148/2016).

\section{References}

1. The Council of Tall Building and Urban Habitat, http://www.skyscrapercenter.com/ research/CTBUH_ResearchReport_2015YearIn Review.pdf. (2015).

2. M. Schlaepfer, J. Lee, L. M. A. Bettencourt, Urban skylines: building heights and shapes as measures of city size, SFI Working Paper: 2015-12-045 (2015).

3. A. Sagun, C. J. Anumba and D. Bouchlaghem, Designing buildings to cope with emergencies: Findings from Case Studies on Exit Preferences, Buildings, Vol 3, 442-461 (2013)

4. A. Cowlard, A. Bittern, C. Abecassis-Empis, J. Torero, Fire safety design for tall building, Procedia Engineering, Vol 62, 169-181, (2013).

5. M. Kealy, Fire engineering supertall: A new approach to escape, CTBUH 2008 8th World Congress, Dubai (2008).

6. J. Shimshori, Tall Building Emergency Evacuation, CTBUH 2005 New York Conference (2005).

7. J. H. Wang and J. H. Sun, Principal aspects regarding to the emergency evaluation of largescale crowds: a brief review of literatures until
2010, Procedia Engineering, Vol. 71, 1-6, (2014).

8. Daeyonggak Hotel Fire, https://en.wikipedia.org/wiki/Daeyeonggak_Hot el_fire. (Accessed on 16 July 2018)

9. H. Yong, https://www.reuters.com/article/ussouthkorea-fire/building-owner-managerarrested-in-south-korean-fire-that-killed-29idUSKBN1EK07Z.

10. History Canada, https://www.history.ca/historytopics/latest/november-3-1974-hotel-fire-endsin-disaster-in-south-korea/

11. 2010 Shanghai Fire, https://en.wikipedia.org /wiki/2010 Shanghai fire.

12. E. Ares, E. Potton and W. Wilson, Grenfell Tower fire: Response and tackling fire risk in high rise blocks, Briefing Paper Number 7993, 2017.

13. The Council on Tall Building and Urban Habitat, http://www.ctbuh.org/News/ Global TallNews/tabid/4810/Article/5962/language/enUS/view.aspx (17 April 2018).

14. The Council on Tall Building and Urban Habitat, http://www.ctbuh.org/News/Global TallNews/CTBUH ReleasesInitialStatementon GrenfellHouse/tabid/7579/language/enUS/Default.aspx (14 June 2017).

15. J. Cox, A. Devlin and D. Collins, https:// www.thesun.co.uk/news/3795199/grenfelltower-apartment-building-london-fire-residentstowel-door-stay-fire-trap-third-world/

16. N. Oxford, https://en.wikipedia.org/wiki/ Grenfell_Tower_fire\#/media/File:Grenfell_Tow er_fire_(wider_view).jpg

17. N. ${ }^{-} \bar{A} l$ Ramahi, https://www.thenational.ae /uae/cigarette-caused-dubai-s-torch-tower-fire1.624072

18. M. Achkhanian, https://gulfnews.com/news/ uae/emergencies/dubai-police-reveal-cause-oftorch-tower-fire-1.2082198

19. CTBUH Global News, http://www.ctbuh.org /News/GlobalTallNews/tabid/4810/Article/5179 /language/en-US/view.aspx

20. https://www.hmetro.com.my/tragediittifaqiyah

21. http://www.sinarharian.com.my/semasa/kebaka ran-tahfiz-tragedi-paling-buruk-2017-1.773335

22. http://www.sinarharian.com.my/semasa/buktidedahkan-pusat-tahfiz-sengaja-dibakar1.733630

23. E. Ronchi, D. Nilsson, Assessment of Total Evacuation Systems for Tall Buildings, Springer-Verlag (2014).

24. Uniform Building By-Laws (UBBL), By-Laws 258- failure of buildings. (1984).

25. Society of Fire Protection Engineers, Guidelines for Designing Fire Safety in Very Tall Buildings, https://www.inti.gob.ar/cirsoc /pdf/fuego/Public_Review_Draft.pdf (2012).

26. HM Government, The building regulation 2010 , Approved Documents B.

27. GSA, Alternate Path Analysis and Design Guidelines for Progressive Collapse Resistance 
(2013).

28. DoD, Design Of Buildings To Resist Progressive Collapse, UFC 4-023-03 (2009).

29. HM Government, The building regulation 2010 , Approved Documents A.

30. A. Wood, Alternative Forms of Tall Building Evacuation, AEI/NIST Conference (2007).

31. M. S. Lee, Performance of the foldable fire staircase for high rise residents, CTBUH 2017 International Conference (2017).

32. X. Zhang, Study on rapid evacuation in highrise buildings, Engineering Science and Technology, an International Journal, Vol 20, Issue 3, (June 2017).

33. https://www.barewalls.com/art-printposter/safety-lifeboat_bwc17139444.html.

34. Escape Chute Devices, https://www. astm.org/SNEWS/MARCH_2005/shimshoni_m ar05.html.

35. https://survitecgroup.com/survitecproducts/152 05/OffshoreMassEvacuationSystem. 